\title{
ARTIGO
}

dO https://doi.org/10.22481/praxis.v15i32.5053

\section{O CONCEITO DE AVALIAÇÃO DA APRENDIZAGEM NO PROGRAMA NOVO MAIS EDUCAÇÃO}

\author{
THE CONCEPTION OF LEARNING EVALUATION BY THE PROGRAMA NOVO \\ MAIS EDUCAÇÃO
}

EL CONCEPTO DE EVALUACIÓN DEL APRENDIZAJE EN EL PROGRAMA NOVO
MAIS EDUCAÇÃO

Heike Schmitz

Universidade Federal de Sergipe - Brasil

Beatriz Noia Souza

Universidade Federal de Sergipe - Brasil

José Luis Monteiro da Conceição

Universidade Federal de Sergipe - Brasil

Resumo: Nesta policy análise focalizamos no conceito de avaliação da aprendizagem no Programa Novo Mais Educação (PNME). Para estabelecer os critérios de análise, recorreu-se ao Quadro de referência de qualidade para escolas em tempo integral, sistematizado pelos pesquisadores alemães Holtappels, Kamski e Schnetzer (2009). Propõe-se responder quais desses critérios de qualidade da escola em tempo integral são também implícitos no conceito de avaliação aplicada no PNME. Para isso foram analisados os documentos oficiais do programa, como também, para fins de comparação, os documentos oficiais da implementação do antigo Programa Mais Educação (PME). Como principal resultado da análise, constata-se que na fase da implementação do PME não foi explicitado a avaliação da aprendizagem dos alunos. No PNME há uma preocupação com a avaliação, mas predomina a avaliação de competências cognitivas, principalmente em Português e Matemática, deixando outras competências e habilidades, como a cooperação e autocompetências, em segundo plano.

Palavras-chave: Avaliação da aprendizagem. Escola em tempo integral. Programa (Novo) Mais Educação.

Abstract: In this policy analysis we focus on the conception of learning evaluation of the Programa Novo Mais Educação (PNME). In order to define criteria for our analysis, we make use of the quality parameters for all-day schools, as systematized by the German researchers Holtappels, Kamski e Schnetzer (2009). Our goal is to answer which quality criteria of all-day schools are considered in the concept of evaluation of the PNME. Therefore, we analyze official documents of the current program's policy as well as, for comparative purposes, documents containing regulations and orientations from the previous Program More Education (PME). As a main result of PMEs principal documents' analysis, we ascertain that there is no mentioning of learning evaluation regarding the 
implementation phase. In documents concerning the implementation phase of the PNME the evaluation of cognitive competencies is predominantly mentioned, primarily concerning Portuguese and Mathematics, leaving other competencies and abilities, such as cooperation and self-competences of secondary importance.

Keywords: Learning evaluation. All-day school. Program (New) More Education.

Resumen: El artículo analiza el concepto de la evaluación del aprendizaje en el Programa Novo Mais Educação (PNME). Con el fin de establecer los criterios de análisis, se recurrió a la clasificación de referencia de calidad de las escuelas de tiempo completo, sistematizado por los investigadores alemanes Holtappels, Kamski e Schnetzer (2009). Se propone identificar cuáles criterios de calidad de la escuela de tiempo completo están implícitos en el concepto de la evaluación aplicada en el PNME. Con ese objetivo, se analizaron los documentos oficiales del programa PNME y de la implementación del antiguo Programa Mais Educação (PME). Como principal resultado del análisis, se constató que en la fase de implementación del PME no fue explicitada la evaluación del aprendizaje de los alumnos. En el PNME hay la preocupación con el aprendizaje de los alumnos, pero predomina la evaluación de competencias cognitivas, principalmente en portugués y matemática, dejando en según plano otras habilidades y capacidades como la cooperación y las autocompetencias.

Palabras clave: Evaluación del aprendizaje. Escuela de tiempo completo. Programa (Novo) Mais Educação.

\section{Introdução}

Uma avaliação somativa ocorre em determinados momentos do processo de ensino, que, entre si, podem ser isolados. Uma avaliação formativa do aluno perpassa, no entanto, todo o processo. Ela tem como objetivo constatar o alcance de objetivos preestabelecidos, e também levantar informações sobre como melhor estimular o desenvolvimento de competências e habilidades pelo aluno e sobre como ele poderá superar suas fraquezas de aprendizagem. Para realizar devidamente uma avaliação formativa, exige-se tempo - um recurso que, em diversas pesquisas empíricas, referentes à produção acadêmica brasileira dos anos de 2010 a 2015, levantadas no Banco de Teses e Dissertações da CAPES e na Biblioteca Digital Brasileira de Teses e Dissertações (BDTD), professores no Brasil declaram não ter. (RABELO, 2010; MILEO, 2011; LOPES, 2012; MARTINS, 2012; SOARES, 2012; GALVÃO, 2013; XAVIER, 2013; ARAUJO, 2014; PEREZ, 2015; SANTOS, 2015).

Por disponibilizar de mais recursos (tempos, espaços e pessoas), parece plausível partir do pressuposto de que a organização do trabalho pedagógico em uma escola em tempo integral ofereça melhores oportunidades para uma avaliação formativa que focaliza no desenvolvimento individual de cada aluno. Além disso, uma educação em tempo integral que se destaca por poder dar melhores condições para uma avaliação formativa individualizada, também deveria, a nosso ver, aplicar um conceito de avaliação da aprendizagem diferenciada, 
já que a escola em tempo integral amplia a sua proposta pedagógica por diversos aspectos (vivências sociais, corporais, culturais, entre outros) que ultrapassam competências cognitivas.

Essa amplitude, a nosso ver, não está sendo oferecida pelas atuais avaliações externas, em âmbito nacional, como, por exemplo, a Avaliação Nacional do Rendimento Escolar (ANRESC) - conhecida como Prova Brasil, devido à finalidade própria dessas, isto é, servir para os atores políticos na formulação de estratégias em prol da melhoria do ensino a partir de uma perspectiva sistêmica. A avaliação externa, de larga escala, em prol do desenvolvimento de políticas eficazes não tem o perfil para servir ao educador como avaliação formativa em prol da aprendizagem individual de cada aluno. ${ }^{1}$ Uma avaliação de natureza somativa, como a das avaliações externas que levantam informações sobre o desempenho de alunos/turmas/séries/escolas em dado momento, constata resultados, os classifica e contribui para rankings, mesmo que o ranqueamento não seja uma intenção explícita. (MARTINS, 2012; BRAGA, 2013; SILVA 2014, BOAS; DIAS, 2015). O educador, porém, para planejar suas atividades pedagógicas precisa de informações sobre as competências e habilidades que os alunos já possuem e informações sobre o porquê do aprender ou não aprender do aluno durante o processo de ensino e aprendizagem. É por meio da avaliação formativa que o professor ganha maiores insights sobre o processo de aprendizagem de cada aluno, realiza o monitoramento e o aconselha no seu desenvolvimento por meio de retornos imediatos a respeito dos seus erros/fraquezas e acertos/potencialidades.

A educação em tempo integral por oferecer mais recursos (tempo, espaço e pessoal) poderá dar melhores condições para uma avaliação com acompanhamento do desenvolvimento individual de cada aluno, no sentido da avaliação diagnóstica, e, principalmente, da avaliação formativa. No entanto, estamos cientes que essas oportunidades a favor de uma avaliação formativa não se estabelecem automaticamente com uma ampliação da jornada escolar. Ela depende, sobretudo, da proposta pedagógica da escola e das condições institucionais, e nessas últimas também se incluem as condições dadas como suporte pela política educacional.

Inquietou-nos, por isso, saber de que forma a política governamental nacional em prol da educação em tempo integral prevê a avaliação da aprendizagem do aluno e de que

\footnotetext{
${ }^{1}$ O Índice de Desenvolvimento da Educação Básica (IDEB) ainda não permite identificar, especificamente, os alunos matriculados na educação em tempo integral. Além disso, não é possível recorrer a esse índice para monitorar a qualidade da educação em tempo integral em si, como já discutido por Schmitz e Souza (2016), e nem para verificar a(s) aprendizagem(ns) do aluno matriculado nela.
} 
forma promete providenciar as condições favoráveis para uma avaliação sob um olhar mais individualizado a respeito do seu desenvolvimento.

A busca por respostas diante dessa inquietação se justifica pelo fato de esperar da educação em tempo integral um benefício na melhoria da aprendizagem do aluno. Ambas as políticas, tanto o Programa Mais Educação (PME) instituído pela Portaria Interministerial $\mathrm{n}^{\circ}$ 17/2007 e regulamentado pelo Decreto ${ }^{\circ} 7.083$, de 27 de janeiro de 2010, como o Programa Novo Mais Educação (PNME), instituído pela Portaria do Ministério da Educação (MEC) n ${ }^{\circ}$ 1.114, no dia 10 de outubro de 2016, intencionam a ampliação da jornada escolar mediante a implementação de ações pedagógicas extraclasse. (BRASIL, 2016a). Enquanto o PME teve como finalidade “[...] contribuir para a melhoria da aprendizagem por meio da ampliação do tempo de permanência de crianças, adolescentes e jovens matriculados em escola pública [...]” (BRASIL, 2010, p. 1), o PNME focaliza nos seus objetivos ainda mais explicitamente na melhoria da " [...] aprendizagem de Língua Portuguesa e Matemática no ensino fundamental, por meio da ampliação da jornada escolar de crianças e adolescentes [...]" (BRASIL, 2016a, p. 23).

As duas políticas propõem o apoio às escolas públicas de Ensino Fundamental na ampliação da carga horária da jornada escolar e, ao mesmo tempo, na diversificação da oferta por meio de atividades extraclasse no contraturno. Além disso, as escolas puderam e podem escolher as demais atividades a serem ministradas entre um leque de ofertas definidas pelo programa, tanto no antigo PME, como no atual PNME.

Os macrocampos do PME foram inicialmente abordados na Portaria Interministerial, explicitando as atividades relacionadas aos campos de artes, cultura, educação, esporte e lazer. (BRASIL, 2007a). Em 2014, ampliaram-se as possibilidades dos macrocampos do conhecimento. As escolas da zona urbana foram contempladas com a opção de escolha entre a comunicação, uso de mídias e cultura digital e tecnológica; cultura, artes e educação patrimonial; educação ambiental, desenvolvimento sustentável e economia solidária e criativa/educação econômica; esporte e lazer; educação em direitos humanos e promoção da saúde. (BRASIL, 2014). As escolas do campo tiveram a escolha relacionada aos macrocampos de Iniciação Científica; Agroecologia; Memória e História das Comunidades Tradicionais, Educação em Direitos Humanos, Cultura, Artes e Educação Patrimonial e Esporte e Lazer. (BRASIL, 2014, p. 21). O PNME continua com a mesma estrutura da divisão em atividades complementares, no entanto, voltou à proposta inicial do PME quando foram implementados, ou seja, com os campos de artes, cultura, esporte e lazer. (BRASIL, 2016a; 
BRASIL, 2016b). Essas atividades extraclasse foram atribuídas aos chamados monitores no PME (BRASIL, 2014) que, no PNME, estão sendo chamados de mediadores da aprendizagem para o acompanhamento pedagógico e de facilitadores para os campos de artes, cultura, esporte e lazer. (BRASIL, 2016b).

O acompanhamento pedagógico no PME previa, pelo menos, uma hora ou uma hora e meia de atividades diárias. (BRASIL, 2014). No Manual Operacional de Educação Integral se formula o foco nas disciplinas de "[...] ciências, filosofia e sociologia, história e geografia, letramento, línguas estrangeiras, matemática e tecnologias de apoio a educação [...]" (BRASIL, 2011, p. 9). No PNME o acompanhamento é ofertado em, pelo menos, cinco horas semanais, dedicado à alfabetização e ao letramento nas disciplinas de língua portuguesa e matemática. São realizadas "[...] 2 (duas) atividades de Acompanhamento Pedagógico, sendo 1 (uma) de Língua Portuguesa e 1 (uma) de Matemática, com 2 (duas) horas e meia de duração cada." (BRASIL, 2016b, p. 6).

Com a implementação do PNME, as escolas podem optar por ofertar esse apoio no desenvolvimento escolar nas matérias de português e matemática, em cinco horas adicionais à jornada escolar regular ou ampliar a jornada escolar por quinze horas semanais, sendo oito horas semanais destinadas ao acompanhamento pedagógico nessas matérias escolares e sete horas semanais distribuídas em demais atividades complementares. (BRASIL, 2016b; BRASIL, 2017; BRASIL, 2018). Essa opção não existia na adesão ao antigo PME que estabelecia uma ampliação da jornada diária de, no mínimo, sete horas com, pelo menos, cinco horas semanais dedicadas ao acompanhamento pedagógico. (BRASIL, 2014). Em resumo, o PME só proporcionava à escola a opção de uma jornada escolar em tempo integral, conforme o conceito estabelecido pela lei. (BRASIL, 2007b). O PNME oferece a opção da jornada em tempo integral ou jornada estendida.

As modificações entre os dois programas não é o foco deste estudo. Apresentamo-las para contextualizar o nosso foco de análise. Focalizamos aqui neste artigo no conceito de avaliação da aprendizagem aplicado pelo PNME. Para atingir esse propósito, foram escolhidos e analisados os documentos que nortearam a implementação da política. Atualmente há acesso aos seguintes documentos que orientam a implementação e operacionalização do PNME: Portaria $n^{\circ}$ 1.145, de 10 de outubro de 2016 sobre a instituição do PNME (BRASIL, 2016a), Documento Orientador de 2016 (BRASIL, 2016b), Caderno de Orientações Pedagógicas, na sua primeira versão (BRASIL, 2017) e o da segunda versão (BRASIL, 2018). 
Escolhemos, para os fins de comparação referente ao PME, os documentos que assumiram funções semelhantes na fase da implementação desse antigo programa no ano 2007/2008: Decreto $n^{\circ}$ 7.083, de 27 de janeiro de 2010 (BRASIL, 2010), Caderno Passo a Passo (BRASIL, 2011), Educação integral: texto referência para o debate nacional (BRASIL, 2009a), Pressupostos para projetos pedagógicos de educação integral (BRASIL, 2009b), e o Manual Operacional de Educação Integral. (BRASIL, 2014). No entanto, a análise desses documentos selecionados, revelou que eles não mencionam explicitamente a avaliação da aprendizagem do aluno.

Descrevemos, em seguida, a utilização do conceito de avaliação nos documentos oficiais anteriormente citados. Não consideramos aqui a avaliação do próprio programa, ou seja, a (auto)avaliação da política. Interessamo-nos a respeito das reflexões sobre a avaliação do aluno e de como a escola pode/deve, conforme o programa, realizá-las. Em segundo momento, lançamos algumas inquietações e socializamos, em terceiro momento, as nossas reflexões, recorrendo, para fins de sistematização a indicadores apresentados em um Quadro de referência de qualidade para escolas em tempo integral, elaborado por pesquisadores alemães.

\section{O conceito de avaliação da aprendizagem no Programa Novo Mais Educação}

Constata-se no Caderno de Orientações Pedagógicas que o professor da escola e, principalmente o mediador do PNME, precisa refletir acerca da avaliação da aprendizagem para que possa ser realizado, com o aluno, um processo de construção e intervenção na sua aprendizagem. Segundo o Caderno de Orientações Pedagógicas, antes de iniciar essas intervenções, é importante refletir a respeito de

I. O que se quer avaliar? II. Como se vai avaliar? III. Como saber se o estudante compreendeu (ou não) os novos conhecimentos? IV. Como saber se os procedimentos foram os mais adequados? V. Como mensurar a aquisição das aprendizagens? VI. Que instrumentos utilizar? VII. Os procedimentos e instrumentos foram os mais coerentes para este ou aquele objetivo? VIII. Os procedimentos e instrumentos foram os mais coerentes para este e aquele estudante? (BRASIL, 2018, p. 40).

A avaliação é parte integrante do ensino e aprendizagem. No PNME, ela tem o intuito primeiramente de avaliar por meio dos testes diagnósticos a alfabetização dos alunos do $1^{\circ}, 2^{\circ}$ e $3^{\circ}$ ano, o Letramento I dos alunos do $4^{\circ}, 5^{\circ}$ e $6^{\circ}$ ano e o Letramento II dos alunos 
do $7^{\circ}, 8^{\circ}$ e $9^{\circ}$ ano do ensino fundamental, referente à português e à matemática. ${ }^{2}$ Por meio destes, são levantados dados sobre habilidades básicas e essenciais em língua portuguesa e matemática, próprias nessa etapa de escolaridade que são desenvolvidas pelos alunos durante o período do ensino fundamental. (BRASIL, 2017; BRASIL, 2018).

Essa avaliação inicial é realizada pelo Centro de Políticas Públicas e Avaliação da Educação $(\mathrm{CAEd})^{3}$ que apresentará os “[...] resultados, a análise pedagógica sobre o desempenho dos estudantes nos testes, bem como o roteiro para leitura e interpretação desses resultados [...]" (BRASIL, 2018, p. 39). Contudo, nos dois Cadernos de Orientações Pedagógicas não se explicita como será feita essa análise pedagógica.

Propõe-se no documento que a partir do resultado da aplicação dos testes, os professores em parceria com a equipe pedagógica da escola desenvolvam estratégias didáticas com a intenção de buscar a superação das dificuldades de aprendizagem identificadas. (BRASIL, 2017; BRASIL, 2018). Além disso, o PNME sugere para os facilitadores e mediadores avaliar o aluno continuamente "[...] para que se evidenciem as aprendizagens ao longo das atividades realizadas [...]”. (BRASIL, 2018, p.39). Avaliar dessa forma, “[...] possibilita o acompanhamento da construção do conhecimento dos estudantes, ao identificar as dificuldades para corrigi-las durante o processo [...]" (BRASIL, 2018, p. 39).

Recomenda-se também para o mediador e o facilitador instrumentos de avaliação, dentre eles a prova, o portfólio, trabalhos individuais e em grupos, debate, observação e a ficha de registro. Alguns instrumentos servem como um auxílio "[...] para todas as áreas do conhecimento, bem como para as atividades complementares do Programa [...]" (BRASIL, 2018, p. 41). Principalmente, o portfólio e a ficha de registro são considerados instrumentos de avaliação oportunos para um monitoramento e acompanhamento das atividades desenvolvidas, como sugerido no Caderno. (BRASIL, 2017; BRASIL, 2018). O portfólio reúne os passos percorridos pelo estudante durante o processo de ensino para fazê-lo ganhar autoconsciência sobre seu processo de aprendizagem por meio de uma análise reflexiva sobre sua atuação na sala de aula. (BRASIL, 2017; BRASIL, 2018). A ficha de registro utilizada pelo mediador e facilitador para observação serve para "[...] registrar as atividades, os avanços, as dificuldades de cada estudante e fazer uma análise crítica e reflexiva sobre cada

\footnotetext{
${ }^{2}$ Alfabetização, Letramento I e Letramento II são termos técnicos do programa que diferenciam diferentes níveis de aprendizagem.

${ }^{3}$ O CAEd, vinculado a Universidade Federal de Juiz de Fora, é uma instituição que operacionaliza (elabora e desenvolve) programas estaduais e municipais destinados a mensurar o rendimento de estudantes das escolas públicas.
} 
um.” (BRASIL, 2017, p.41). Esta ficha pode ser construída de acordo com o critério elaborado pelo mediador, assim sugerem os Cadernos. (BRASIL, 2017; BRASIL, 2018).

Aborda-se nas versões do Caderno de Orientações Pedagógicas a avaliação coletiva, que pode acontecer no conselho de classe, e o envolvimento do aluno na sua própria avaliação. (BRASIL, 2017; BRASIL, 2018). No PNME reconhece-se a importância da “[...] coparticipação dos estudantes nessa maneira de avaliar, pois é necessário que os estudantes tenham consciência de suas aprendizagens e, também, se responsabilizem por elas". (BRASIL, 2018, p. 39). Nesse ínterim, “[...] torna-se significativo que o estudante não apenas se auto avalie, mas o faça com os sujeitos envolvidos em todo o processo pedagógico do Programa Novo Mais Educação.” (BRASIL, 2018, p. 39).

\section{Reflexões acerca do conceito de avaliação aplicado no Programa Novo Mais Educação}

A avaliação cabe ao trabalho docente, e, consequentemente, à competência do professor e educador. O próprio programa também explicita esse pressuposto, pois as avaliações externas são apontadas no Caderno de Orientações Pedagógicas como “[...] auxiliares para a organização, planejamento e reorganização do trabalho dos professores, articuladores, mediadores e facilitadores com vistas à melhoria das aprendizagens [...]" (BRASIL, 2018, p. 45; grifo nosso).

Constata-se, explicitamente que o docente “[...] deve ter consciência do uso dos instrumentos avaliativos e suas potencialidades [...]” (BRASIL, 2018, p. 41). No que diz respeito aos papéis dos mediadores e os facilitadores, os documentos orientadores mencionam a função de realizar o monitoramento do processo de avaliação do aluno e das tarefas realizadas. Além disso, possuem os papéis de descobrir o instrumento de avaliação adequado aos seus alunos, bem como fazer a análise dos resultados. Também é papel desses atores, a busca pela superação das dificuldades dos discentes através da correção e feedback contínuo no processo de aprendizagem. (BRASIL, 2017; BRASIL, 2018).

Nas duas versões do Caderno de Orientações Pedagógicas são descritos explicitamente os perfis desejados para atuar como facilitadores e mediadores no PNME. (BRASIL, 2017; BRASIL, 2018). Tanto para mediadores do acompanhamento de língua portuguesa e matemática nos anos iniciais, como nos anos finais do ensino fundamental, recomendam-se professores, estudantes, universitários e educadores populares com experiência. Para realizar o acompanhamento nos anos iniciais deseja-se, de preferência, 
I. professores com pós-graduação em educação;

II. professores licenciados em Pedagogia;

III. professores com ensino médio na modalidade normal;

IV. estudantes do curso de Licenciatura em Pedagogia; e,

V. educadores populares que concluíram o ensino médio, que demonstrem experiência com educação integral na área de alfabetização. (BRASIL, 2018, p. 7).

Para os anos finais, são recomendados como mediadores para matemática

I. professores com pós-graduação em educação matemática;

II. professores com licenciatura em Matemática;

III. estudantes do curso de Licenciatura em Matemática;

IV. estudantes medalhistas da Olimpíada Brasileira de Matemática das

Escolas Públicas - OBMEP; e,

V. educadores populares que concluíram o ensino médio com experiência no acompanhamento pedagógico em Matemática. (BRASIL, 2018, p. 7-8).

E para o acompanhamento em língua portuguesa,

I. professores com pós-graduação em educação e letras;

II. professores formados em Letras - Português;

III. estudantes do curso de Letras - Português;

IV. estudantes premiados na Olimpíada Brasileira de Língua Portuguesa; e,

V. educadores populares com experiência no acompanhamento pedagógico em Língua Portuguesa. (BRASIL, 2018, p. 8).

Para realizar as outras atividades complementares, recomenda-se, de acordo com os documentos orientadores do programa, que o facilitador tenha experiência com o seu âmbito de atuação. (BRASIL, 2017; BRASIL, 2018). Na coordenação pedagógica das atividades ofertadas na escola, o articulador, por sua vez, desenvolverá, conforme programa, suas atividades com base na avaliação feita pelos professores da escola. (BRASIL, 2018) O Caderno de Orientações estabelece que

[...] o articulador deve conversar com os professores da escola, a fim de receber feedback em relação ao processo de aprendizagem e desenvolvimento dos estudantes inscritos no Programa. Essas conversas devem subsidiar o planejamento das ações tanto no acompanhamento pedagógico como nas outras atividades. (BRASIL, 2018, p. 19).

Essas orientações gerais fornecidas nos documentos do PNME para descrever o conceito de avaliação do aluno aplicado nesse programa, se referem a um conhecimento que os professores já devem possuir, devido a sua formação inicial. É, então, necessário que os formuladores de uma política educacional abordem aspectos dos processos avaliativos a serem feitos pelos professores e pessoas atuantes no programa e recomendá-los instrumentos para tal? Essa inquietação poderá surgir, no entanto, parece plausível a preocupação por parte 
dos atores políticos já que, nos últimos dez anos, aos resultados de diversas pesquisas acadêmicas brasileiras sobre a avaliação educacional, levantadas por meio de estudos de caso, apontam à necessidade de conscientização do professor. (GUIMARÃES, 2010; RABELO, 2010; KREISCH, 2011; FAVARÃO, 2012; NASCIMENTO, 2012; SALES, 2012; SIBILA, 2012; SOARES, 2012; CARDOSO, 2013; LAZARI, 2013; RIBEIRO, 2014; ARAÚJO, 2014; OLIVEIRA, 2015). Considerando que resultados de estudos de caso não podem ser generalizados, essas pesquisas, podem servir, no entanto, como alerta da demanda de mais dados científicos a respeito a fim de sondar se trata-se de um fenômeno comum ou de excepções.

Além disso, parece-nos plausível explicitar as reflexões gerais sobre a avaliação dos alunos diante do fato de que os facilitadores nem sempre são pessoas com conhecimento pedagógico. Como vimos, enquanto se busca atribuir a responsabilidade de monitorar o acompanhamento pedagógico por pessoas com certo conhecimento pedagógico, nas atividades complementares também podem atuar pessoas que não o apresentam. Como inicialmente já mencionamos, nos parece oportuna a avaliação do aluno também nessas atividades justamente para poder acompanhar devidamente o desenvolvimento individual dos alunos sob múltiplas perspectivas. Voltaremos novamente a esse argumento mais diante.

As explicitações em torno da avaliação do aluno, especialmente no Caderno de Orientações Pedagógicas, revelam um anseio em prol da avaliação formativa. No entanto, a intromissão no trabalho escolar do professor e educador por órgãos externos pode, a nosso ver, se tornar uma influência negativa a esse anseio. Há estudos de caso que revelam que os professores utilizam (os resultados de) avaliações externas para treinar os estudantes com a intenção de aumentar o desempenho nos resultados destas avaliações. (SANTOS, 2010; CORDEIRO, 2014; SZATKOSKI, 2014; COSTA, 2015; MENEGÃO, 2015). Novamente estamos cientes que resultados de estudos com âmbito limitado, devido à sua escolha metodológica, não podem ser generalizados, mas os consideramos como um alerta para uma reflexão crítica.

É preciso ponderar que questões didáticas e metodológicas, tomadas pelos professores no seu planejamento, são (ou devem ser) interligadas com as questões da avaliação da aprendizagem. O Caderno de Orientações Pedagógicas estabelece como objetivo da avaliação "[...] identificar os progressos e as dificuldades, analisar metas e corrigir rumos, se for o caso [...]" (BRASIL, 2018, p. 36). 
Para isso, porém, instrumentos de avaliação precisam ajudar a obter informações da situação de aprendizagem dos alunos de modo que possam servir como ponto de partida para que o próprio professor possa planejar e/ou organizar ações pedagógicas a favor da construção do conhecimento. Esta estruturação começará pelas escolhas metodológicas de como serão trabalhados os conteúdos conforme as reais necessidades individuais e coletivas do aluno para que este alcance os objetivos educacionais previstos para seu nível escolar. (GARCIA; TENÓRIO, 2012).

Os dados levantados por testes padronizados e sua interpretação por órgãos externos, além de interferir na autonomia do professor, não conseguem considerar adequadamente o planejamento de cada professor e o contexto escolar o qual esse reconsidera. Concordamos com Martins (2001) que a metodologia adotada pelas avaliações externas “[...] desconsidera a diversidade cultural que permeia as redes de escolas não captam a efetiva dinâmica das unidades escolares, com base apenas nos resultados finais obtidos por testes padronizados." (MARTINS, 2001, p. 34).

Por isso, inquietamo-nos com os testes de Alfabetização e Letramento I e II aplicados com os alunos do Ensino Fundamental proposto pelo PNME e sobre sua utilidade para uma avaliação formativa do aluno pelo professor. Essa questão poderá, porém, ser respondida apenas em futuras pesquisas, assim que se torne possível medir o impacto da mudança implementada pelo novo programa.

Os documentos não explicitam claramente se o resultado do diagnóstico, feito por terceiros, é devolvido ao professor com informações por discente ou turma, mas atualmente, o CAEd, elabora testes que a escola baixa por meio de um sistema eletrônico e os aplica com seus alunos. Em seguida, são preenchidas, pela escola, no sistema as respostas dos estudantes e o próprio sistema do CAEd gera automaticamente os resultados quantitativos (margem de acertos) por aluno ${ }^{4}$. Um percentual de acertos por aluno informa ao professor quem precisa de maior ajuda, ou seja, esclarece a necessidade de flexibilizar e individualizar o seu planejamento pedagógico, porém, o professor precisa desenvolver a competência para analisar os resultados do teste de modo a identificar a causa e/ou o porquê dos erros cometidos por cada aluno. Diante disso, parece plausível que o PNME aponte que a avaliação é tarefa do

\footnotetext{
${ }^{4}$ Mas cabe aqui esclarecer: o monitor só tem acesso ao CAEd se a escola já recebeu os recursos financeiros do referente ano. Escolas que foram por algum motivo ainda não contempladas, não tem acesso ao CAEd enquanto se resolve a situação financeira.
} 
professor, dos mediadores e facilitadores, inclusive com os alunos, para construir e intervir na aprendizagem deles. (BRASIL, 2017; BRASIL, 2018).

A principal crítica aqui lançada por nós, é que o apoio dado aos educadores se refere aos critérios da aprendizagem cognitiva, a respeito da alfabetização e letramento em português e matemática, enquanto os demais tipos de aprendizagem oportunizados pela educação em tempo integral estão sendo negligenciados. Quais seriam esses tipos de aprendizagem? Quais são os critérios para avaliá-los? Para delinear critérios e indicadores para a avaliação da aprendizagem recorreu-se a um Quadro de referência para a qualidade da escola em tempo integral, elaborado por pesquisadores alemães que já foi comentado em partes, por Schmitz e Souza (2016) e Schmitz e Kamski (2018).

\section{Critérios e indicadores da qualidade da escola em tempo integral}

No Quadro de referência de qualidade para escolas em tempo integral, apresentado por Holtappels, Kamski e Schnetzler (2009), são listados indicadores sobre diversos aspectos da escola em tempo integral, considerando aspectos relacionados a condições externas (input) que a escola em tempo integral enfrenta/aproveita, a condições da operacionalização interna (processos) da educação integral pela escola e aos resultados (output) da educação em tempo integral. Com isso, eles formularam uma ferramenta que servem para orientar, tanto os atores políticos e avaliadores no monitoramento da qualidade da educação em tempo integral, como também os atores escolares na elaboração da proposta pedagógica, e na sua implementação / consolidação e na avaliação institucional. Os critérios e indicadores que constam no Quadro de referência de qualidade para escolas em tempo integral são oriundos de reflexões teóricas, abordagens/expectativas políticas, e de resultados de pesquisas empíricas. Compreende-se, por isso, o quadro como uma ferramenta dinâmica a ser complementada continuamente a depender de novos insights científicos.

Por ser o foco aqui a avaliação da aprendizagem do aluno, o nosso interesse se concentra nos critérios e indicadores referentes ao output, ou seja, aos resultados da educação em tempo integral. Inquietamo-nos, por isso, em saber o que se poderá considerar na avaliação do resultado da educação em tempo integral? E isso implica a pergunta: o que se poderá avaliar na aprendizagem do aluno? Essas duas perguntas operacionais para a discussão de indicadores da avaliação são discutidas para analisar o conceito de avaliação da aprendizagem no Programa Novo Mais Educação. 
Referente ao output, Holtappels, Kamski e Schnetzer (2009) distinguem quatro áreas: a) os resultados e o sucesso escolar por ter frequentado uma escola em tempo integral; b) competências disciplinares e competências além das disciplinas; c) competências sociais, e, d) bem-estar e satisfação. A essas áreas, por sua vez, se associam diversos indicadores, entre eles, vinte que se referem à avaliação da aprendizagem. Apresentamos neste artigo um conjunto de indicadores ${ }^{5}$ ligados a determinado aspecto e depois de cada conjunto de indicadores, eles serão comentados no contexto da proposta do $\mathrm{P}(\mathrm{N}) \mathrm{ME}$.

Para avaliar a qualidade do processo da avaliação da aprendizagem se formulou três indicadores:

- Indicador A: Existe uma avaliação transparente da aprendizagem, acessível a todos os profissionais e usada por todos os profissionais para uma orientação individual do aluno.

- Indicador B: Trabalha-se para os fins da autoavaliação de aprendizagem com o portfólio.

- Indicador C: Avaliações externas estão inseridas no desenvolvimento da concepção da educação e na oferta da jornada ampliada.

Trazido ao contexto do Programa Novo Mais Educação, compreendemos, com relação ao Indicador A, que a implementação de um sistema de monitoramento, como o CAEd, pode contribuir na formulação de critérios preestabelecidos, claros e transparentes para a avaliação nas disciplinas de português e matemática. No entanto, se esses critérios não são construídos em conjunto com os profissionais que estão envolvidos na operacionalização do programa, ou seja, com aquelas pessoas (professores, mediadores e facilitadores) que interagem com as crianças e jovens, corre-se um maior risco de não conhecer, compreender ou aplicá-los. Além disso, apontamos a restrição nas competências e habilidades de português e matemática, prevista no PNME. Aqui então percebemos a necessidade de adotar outras medidas tanto na ampliação e diversificação de aspectos quanto a conscientização dos professores, mediadores e facilitadores sobre a avaliação do aluno.

No que diz respeito ao Indicador B foi destacado, também no PNME, o portfólio como um instrumento de autoavaliação do aluno para estimular o envolvimento desse na

\footnotetext{
${ }^{5}$ Os indicadores foram traduzidos livremente por nós e identificados com letras para fins da melhor distinção nesta publicação.
} 
reflexão sobre seu processo de aprendizagem. Isto consideramos favorável, porque pesquisas empíricas demonstram benefícios do uso desse instrumento no processo de ensino e aprendizagem, mencionando aqui apenas para fins de dar exemplos, o estudo de Bona (2010) e Cerminaro (2013).

No que diz respeito à avaliação externa (Indicador C), tanto o PME (BRASIL, 2010) esperava, como o PNME (BRASIL, 2016a) espera com a implementação da educação em tempo integral uma melhoria no desempenho educacional do aluno e no combate a distorção idade/série e evasão, o que implica a expectativa de melhorar o IDEB por serem indicadores desse índice. No entanto, a questão que precisa ser investigada é se cada escola formulou uma concepção de educação em tempo integral ou jornada estendida e construiu uma oferta específica de atividades conforme os dados obtidos por meio da avaliação externa, ou seja, da Prova Brasil. Para melhorar o IDEB, implica-se a melhoria do desempenho dos alunos, e o combate da reprovação. Esse esforço da escola exige um diagnóstico que revela o porquê do baixo desempenho e por qual motivo os alunos abandonam a escola ou são reprovados. Faz-se necessário reflexões sobre os processos internos de ensino e aprendizagem nas instituições.

Formulou-se indicadores no Quadro de referência de qualidade para escolas em tempo integral também a respeito de um acompanhamento mais individualizado, inclusive para evitar reprovações, tais como:

- Indicador D: Existe um plano de promoção especialmente orientado para alunos que reprovaram (Escola de Verão/ Concepção de promoção durante o segundo semestre do ano letivo, etc.).

- Indicador E: Existem medidas de prevenção para evitar insucesso escolar.

- Indicador F: Existe um plano da escola para a promoção de focos no desenvolvimento (diagnóstico de problemas de aprendizagem / problemas pessoais de desenvolvimento / técnicas de trabalho, etc.) elaborado e desenvolvido por todos os profissionais da jornada ampliada para evitar reprovação.

No PME era explicitamente mencionada a intenção de evitar o insucesso escolar e melhorar o desempenho dos alunos e para isso se formulou a articulação entre diversos ministérios e instituições. (BRASIL, 2009a). A Portaria Interministerial no 17/2007 mencionava que uma das finalidades do programa era desenvolver ações pedagógicas com a intenção de melhorar o combate contra a evasão escolar, os índices de reprovação e a distorção idade-série. (BRASIL, 2007a). O PNME propõe implantar, por meio das atividades de acompanhamento pedagógico e atividades complementares, ações pedagógicas para 
melhorar o rendimento e o desempenho escolar dos estudantes. (BRASIL, 2016a; BRASIL, 2016b; BRASIL, 2017; BRASIL, 2018). Ambos os programas orientam, de forma geral, como organizar as atividades de acompanhamento pedagógico e atividades complementares, preocupando-se, no entanto, muito mais com a organização dos tempos escolares (atividades escolares, acompanhamento, atividades complementares). Nos documentos aqui analisados, não se encontrou a recomendação para que as escolas e os professores e educadores nelas atuantes elaborassem um plano específico ou desenhassem estratégias de aprendizagem para aqueles alunos que apresentassem dificuldades de aprendizagem, como expresso nos Indicadores D, E e F.

Vale aqui ressaltar que o Indicador F tematiza que os problemas apresentados na aprendizagem podem ter origens diversas, inclusive problemas pessoais de desenvolvimento, ou seja, não são sempre oriundos a dificuldades cognitivas de aprendizagem. Isso torna-se ainda mais relevante já que a oferta escolar em tempo integral se destina, assim previa o PME (BRASIL, 2011) e prevê o PNME (BRASIL, 2016a), a alunos de regiões mais vulneráveis. Cabe à avaliação da aprendizagem, sobretudo numa educação em tempo integral, captar outras dimensões do desenvolvimento do aluno, como, por exemplo, sua resiliência, suas estratégias de estudos autônomos, seu comportamento social, sua capacidade de trabalhar em equipe. São esses, entre outros, aspectos relevantes a serem monitorados.

A respeito do desenvolvimento das competências referentes a disciplinas escolares o Quadro de referência de qualidade para escolas em tempo integral contém cinco indicadores. São eles:

- Indicador G: A escola possui um sistema de monitoring para avaliar e documentar o desenvolvimento de competências dos alunos nas disciplinas.

- Indicador H: Resultados e produtos de aprendizagem estão sendo verificados e analisados a respeito do modo e do nível no contexto das tarefas e arranjo da aprendizagem.

- Indicador I: Na realização da educação em tempo integral focaliza-se na diminuição das diferenças de desempenho dos alunos referentes a competências nas disciplinas.

- Indicador J: A oferta em tempo integral contém oportunidades de aprendizagem para melhorar e aprofundar competências e capacidades dos alunos nas diversas disciplinas.

- Indicador K: Busca-se abordagens para compensar, de maneira possível, as desigualdades (familiares e de gênero) nas disciplinas. 
Um registro sistemático próprio da escola sobre a aprendizagem dos alunos nas disciplinas, que ultrapassa o registro de notas de unidades em diários de classe, facilita a identificação de dificuldades de aprendizagem de uns e do avanço dos outros para formular estratégias de ensino mais individualizado aos alunos matriculados na educação em tempo integral. Para tal precisa-se uma reflexão coletiva sobre critérios de avaliação entre professores, mediadores e facilitadores. Como já apontamos, a reformulação da política da educação em tempo integral levou a uma restrição da oferta e do foco do acompanhamento pedagógico. Enquanto no PME ainda se deu a oportunidade do acompanhamento pedagógico de diversas matérias escolares (geografia, história, sociologia, filosofia, língua estrangeira, tecnologia de apoio a alfabetização, ciências, matemática e língua portuguesa), o PNME dá ênfase especificamente na alfabetização e letramento nas disciplinas de matemática e língua portuguesa. No entanto, um sistema de monitoramento de competências e habilidades dos alunos proporcionará maiores informações se não se restringir apenas a competências em português e matemática. Além disso, há de se, por um lado, refletir sobre como inserir o sistema de monitoramento elaborado pelo CAEd e seus resultados em um registro sistemático próprio da escola para que os dados se complementem e possam servir em âmbito da gestão escolar e coordenação pedagógica como base de tomada de decisão no planejamento estratégico da instituição de ensino, e, por outro lado, sobre a correspondência dos produtos de avaliação (testes) fornecidos pelo CAEd com o modo e o nível das tarefas e do arranjo da aprendizagem ofertados no âmbito escolar, como tematizado no Indicador H.

No que diz respeito ao Indicador $\mathrm{K}$, constatamos que o PNME se preocupa com a questão da desigualdade social e que se busca diminuir as desvantagens a ela articuladas. $\mathrm{O}$ mesmo era previsto no PME através do decreto, porém, o Ministério da Educação (MEC) estipulava todo ano qual seria o público-alvo com prioridade. (BRASIL, 2010). A oferta da educação em tempo integral no PNME é destinada para crianças e jovens em situação de risco e vulnerabilidade social, em situação de risco nutricional, como também para alunos repetentes, alunos em distorção idade/ano, com alfabetização incompleta e que apresentam lacunas de aprendizagem em Língua Portuguesa e Matemática e que se encontram em situação provisória de dificuldade de aprendizagem em Língua Portuguesa e Matemática (BRASIL, 2017). O PNME aponta explicitamente a importância de que

[...] os grupos sejam heterogêneos, a fim de possibilitar a aprendizagem entre pares. Isso significa que a escola deve selecionar estudantes que não estão necessariamente em nenhum dos grupos acima, mas que demonstrem interesse em participar das atividades propostas e em passar mais tempo na 
escola. Esses estudantes podem exercer liderança no grupo, motivando os colegas a superarem suas dificuldades e, em razão do sucesso escolar que possuem, estão em condições de mediar a aprendizagem dos colegas. (BRASIL, 2017)

Os indicadores não se restringem a uma oferta de apoio específico (acompanhamento pedagógico) relacionada às matérias escolares. Pode-se ofertar oportunidades de aprendizagem em diversas situações nas quais os alunos desenvolvem competências e capacidades que também ajudam no desempenho de disciplinas, como mostra o Indicador J. Por exemplo, podem, numa oficina de Skate, ser trabalhadas as capacidades que servem para cálculos matemáticos ou físicos, ou, numa oficina de teatro, podem se desenvolver habilidades linguísticas e de expressão corporal. Nessas oficinas, aqui citadas como exemplo, se trabalha competências associadas a objetos de conteúdo de determinadas disciplinas, mas também trabalham competências e capacidades que servem para outros objetivos educativos, como, por exemplo, autocompetências como lidar com estresse, desenvolver resiliência, aceitar crítica, que inclusive devem, a nosso ver, ser também objetivos explícitos de aprendizagem e, por isso, ser avaliados.

O Quadro de referência de qualidade para escolas em tempo integral contém indicadores a respeito de outras competências:

- Indicador L: Oferece-se oportunidades de aprendizagem para a aquisição de conhecimento de disposição e orientação e de uma consciência do meio ambiente e sustentabilidade.

- Indicador M: Oferece-se oportunidades de aprendizagem para o uso de tecnologias, sua aplicação, análise e avaliação crítica de mídias novas e produtos mediais.

- Indicador N: A educação em tempo integral contém oportunidade de aprendizagem para que alunos adquiram estratégias de aprendizagem como também técnicas de aprendizagem e trabalho (pesquisa de informação, técnicas de apresentação, trabalho com planos, tabelas, gráficos, etc.).

- Indicador O: Oferece-se oportunidades para o desenvolvimento de competências motivacionais, emocionais e volitivas (competência para autogestão).

- Indicador P: Oferece-se oportunidades de aprendizagem para a aquisição de competências de planejamento e solução de problemas.

- Indicador Q: Oferece-se oportunidades de aprendizagem para a aquisição de capacidades para um pensamento sistêmico e competência de análise. 
- Indicador R: Oferece-se oportunidades de aprendizagem para a aquisição de competências de avaliação/julgamento e tomada de decisão.

- Indicador S: Oferece-se aos alunos oportunidades e espaços de aprendizagem para o desenvolvimento de uma aprendizagem autônoma.

- Indicador T: A escola possui um sistema de monitoring para avaliar e documentar o desenvolvimento de competências dos alunos além das disciplinas.

No que diz respeito ao Indicador L, o PME ainda ofereceu oportunidades de aprendizagem relacionada à consciência ecológica através do macrocampo meio ambiente. (BRASIL, 2011; BRASIL, 2014). Já o PNME não contém um macrocampo específico ${ }^{6}$. A respeito do Indicador M sobre oportunidades de aprendizagem para o uso de tecnologias, o PME oferecia no macrocampo de cultura digital atividades de software educacional/Linux Educacional, informática e tecnologia da informação e ambiente de redes sociais, e, além disso, eram ofertadas, no macrocampo de comunicação e uso de mídias, atividades como: jornal escolar, rádio escolar, histórias em quadrinhos, fotografia e vídeo. (BRASIL, 2011). Esses macrocampos não são mais ofertados no PNME, mas lembrando que nos anos da implementação do PME, como política introdutora (BRASIL, 2014), as escolas já haviam a oportunidade de aquisição de material e equipamentos. Assim, os conteúdos desses macrocampos podem ser trabalhados também nas atividades de acompanhamento pedagógico de Língua Portuguesa e Matemática e nas outras atividades complementares. O PNME recomenda por meio do acompanhamento pedagógico de matemática que o mediador da aprendizagem "[...] incentive o uso crítico de novas tecnologias como: softwares, aplicativos e calculadoras." (BRASIL, 2017, p.31) para construção e reconstrução do conhecimento matemático.

Em relação ao Indicador N, o PNME aborda, como vimos, nos seus documentos a questão da participação do aluno no seu processo de ensino-aprendizagem. Preocupa-se que o aluno desenvolva uma aprendizagem autônoma e seja, o principal agente de transformação da sua própria aprendizagem. Para isso, o PNME propõe aos mediadores e facilitadores

\footnotetext{
${ }^{6}$ No entanto, no ato de adesão, a escola tem atualmente a possibilidade de escolher atividades relacionadas ao meio ambiente, como a horta escolar.
} 
desenvolver atividades em sua prática pedagógica que envolvam pesquisas individuais e trabalhos em grupos. Essas estratégias de aprendizagem podem ajudar o aluno a desenvolver seu senso crítico, expressar suas ideias e tomar posições. Além disso, permitem o exercício da autonomia (quando individual) e da negociação (quando coletivo). (BRASIL, 2017; BRASIL, 2018).

Para que o aluno desenvolva diversas competências, tais como: a autogestão, pensamento sistêmico, competência de análise, técnicas de aprendizagem e trabalho, de planejamento e solução de problemas e de avaliação, julgamento e tomada de decisão (tematizados nos Indicadores $\mathrm{O}, \mathrm{P}, \mathrm{Q}$, e R),é preciso que o próprio programa dê condições necessárias para que o aluno possa participar efetivamente como sujeito do programa, para que ele possa tomar decisões, por exemplo, sobre a escolha de oficinas nas quais quer participar, sobre estratégias assertivas e estudos autônomos (individuais ou em pares) para resolver os problemas de aprendizagem sem depender de adultos. Cabe à gestão escolar pensar em horas e espaços dedicados a estudos autônomos dos alunos, como mencionado no Indicador S, e na flexibilização da oferta da educação em tempo integral para que cada aluno possa respeitar seu ritmo (estudos, descanso, lazer, momentos em coletivo e momento em silêncio, consigo mesmo).

Enfim, um dos indicadores que, a nosso ver, merece ser enfatizado é o Indicador S sobre a existência de um sistema de monitoramento da aprendizagem do aluno a respeito de competências além das disciplinas, ou seja, também além das competências cognitivas disciplinares. Justamente por ter dirigido o foco da avaliação a aprendizagem da alfabetização e do letramento em língua portuguesa e matemática, com apoio externo (via CAEd), corre-se, no PNME, o risco da escola deixar para segundo plano um acompanhamento do desenvolvimento de outras competências e habilidades - capacidades do aluno.

\section{Considerações finais}

Os documentos orientadores da implementação do antigo PME não explicitam o conceito de avaliação da aprendizagem. Considera-se louvável a preocupação com a conscientização dos professores e colaboradores que atuam no PNME a respeito da avaliação do aluno, desde o início da sua implementação. No entanto, o foco está no diagnóstico do desempenho do aluno nas suas competências em português e matemática. Para tal, se transfere ao CAEd a competência de elaborar testes padronizados. Por ser padronizados, há, mesmo se 
isso não fosse a intenção, o risco desses serem usados para criar rankings, ou seja, classificar as escolas em vez de servir para uma avaliação formativa do aluno.

$\mathrm{O}$ programa deixa à responsabilidade do professor de planejar e administrar os processos da avaliação formativa e providenciar os instrumentos e indica alguns instrumentos avaliativos que podem ser utilizados também pelos facilitadores, mediadores e professores, tais como o portfólio. (BRASIL, 2017; BRASIL, 2018). Aponta-se, no contexto da avaliação, a cooperação indispensável entre professores, articuladores e facilitadores/mediadores quando indica que os articuladores devem se referir nas suas atividades aos resultados da avaliação dos professores dos alunos, como anteriormente já citada. (BRASIL, 2017; BRASIL, 2018).

No entanto, não se descreve de que forma a avaliação pode ser aplicada e aproveitada de forma diversificada por ter uma jornada escolar estendida e/ou em tempo integral. Por exemplo, por poder interagir com o aluno em diversas situações (tempo, espaço, grupos diferentes) nas atividades proporcionadas pelos facilitadores e mediadores, disponibiliza-se ao professor, mais e outras informações e, consequentemente, também mais oportunidades de (re-)ajustes pela equipe pedagógica quando houver necessidade.

Com a diversificação da oferta das atividades complementares se criam oportunidades para avaliar competências sociais, por exemplo, um comportamento cooperativo, ou auto competências, como, por exemplo, a resiliência, que também, ou, sobretudo, definem a qualidade da educação em tempo integral. Assim como alertado por Arroyo (2012) a respeito da educação em tempo integral que as escolas não devem ofertar mais do mesmo; assim apontamos aqui que em uma escola em tempo integral não se deve avaliar mais do mesmo do mesmo jeito.

As indicações dadas no PNME se referem em geral ao desenho do programa e direciona-se principalmente aos professores, facilitadores e mediadores. A nosso ver, pouco se direciona à gestão escolar e a coordenação pedagógica, cuja tarefa é proporcionar as condições favoráveis pelo processo de ensino e aprendizagem como coordenar os esforços individuais para que eles em sintonia se juntem em prol de objetivos comuns. Principalmente para um planejamento estratégico dos processos educacionais há de se partir de resultados de avaliação cujos critérios e indicadores são coletivamente preestabelecidos e trabalhados. Por isso recorremos aqui ao Quadro de referência de qualidade para escolas em tempo integral como base da análise dos documentos do $\mathrm{P}(\mathrm{N}) \mathrm{ME}$. Os indicadores apresentados estão em parte também, indiretamente, presentes no PNME, mas restam conteúdos indicados ainda 
ausentes - indicadores a respeito de aspectos que justamente destacam as oportunidades da educação em tempo integral, comparada com a educação regular em um único turno.

Podemos resumir: a dimensão da avaliação é considerada no PNME mais do que no PME, no entanto, não se esclareceu claramente indicadores que especificam a qualidade da educação em tempo integral a ser alcançada. A formulação de indicadores diversos e claros, facilitaria o trabalho de gestores e coordenadores para que esses, no âmbito das atribuições que lhes competem, pudessem proporcionar as condições necessárias. Uma listagem de critérios de qualidade e de possíveis indicadores, assim como elaborado pelos pesquisadores alemães Holtappels, Kamski e Schnetzer (2009), poderia servir como ponto de partida para uma reflexão coletiva, um planejamento e monitoramento no desenvolvimento organizacional das escolas em tempo integral.

\section{REFERÊNCIAS}

ARAUJO, André Wangles de. Análise do modelo de avaliação de aprendizagem de uma escola pública do Distrito Federal na percepção dos docentes. 2014. Dissertação (Mestrado em Matemática). Universidade de Brasília, Distrito Federal, 2014.

ARROYO, Miguel. O direito a tempos-espaços de um justo e digno viver. In: MOLL, Jaqueline. Caminhos da educação integral do Brasil: direito a outros tempos e espaços educativos. 1. ed. Porto Alegre: Penso, 2012. p. 33-45.

ARRUDA, Jeferson de. $O$ uso das avaliações escritas de Matemática no $9^{\circ}$ ano do ensino fundamental em escolas públicas do Gama-DF. 2015. Dissertação (Mestrado em Matemática). Universidade de Brasília, Brasília, 2015.

BOAS, Benigna Maria de Freitas Villas; DIAS, Elisângela Teixeira Gomes. Provinha Brasil e avaliação formativa: um diálogo possível?. Educar em revista, Curitiba, n. 1, p. 35-53, 2015. Disponível em: < www.scielo.br/pdf/er/nspe1/1984-0411-er-1-spe-00035.pdf >. Acesso em: 15 jan. 2017.

BONA, Aline Silva de. Portfólio de Matemática: um instrumento de análise do processo de aprendizagem. 2010. Dissertação (Mestrado em Ensino de Matemática). Universidade Federal do Rio Grande do Sul, Porto Alegre, 2010.

BRAGA, Marcela Soares Campos. (Auto) avaliação da aprendizagem: uma investigação sobre suas possibilidades nos anos iniciais do ensino fundamental. 2013. Dissertação (Mestrado em Educação). Universidade Federal do Estado do Rio de Janeiro, Rio de Janeiro, 2013. 
BRASIL. Portaria Normativa Interministerial no 17, de 24 de abril de 2007. Institui o Programa Mais Educação, que visa fomentar a educação integral de crianças, adolescentes e jovens, por meio do apoio a atividades sócio-educativas no contraturno escolar. Diário Oficial da União, Brasília, DF, 26 abr. 2007a.

BRASIL. Decreto $n^{\circ} 6.253$, de 13 de novembro de 2007. Dispõe sobre o Fundo de Manutenção e Desenvolvimento da Educação Básica e de Valorização dos Profissionais da Educação - FUNDEB, regulamenta a Lei n⿳ำ 11.494, de 20 de junho de 2007, e dá outras providências. Diário Oficial da União. Brasília, DF, 13 nov. 2007 b.

BRASIL. Ministério da Educação. Educação integral: texto referência para o debate nacional. Brasília, 2009a. Disponível em: <http://portal.mec.gov.br/dmdocuments/cadfinal_educ_integral.pdf >. Acesso em: 15 jul. 2018.

BRASIL. Ministério da Educação. Rede de saberes mais educação: pressupostos para projetos pedagógicos de educação integral: caderno para professores e diretores de escolas. 1 . ed. Brasília, 2009b. Disponível em:

<portal.mec.gov.br/dmdocuments/cad_mais_educacao_2.pdf>. Acesso em: 15 jul. 2018.

BRASIL. Decreto n ${ }^{\circ} 7.083$, de 27 de janeiro de 2010. Dispõe sobre o Programa Mais Educação. Diário Oficial da União, Brasília, DF, 27 jan. 2010.

BRASIL. Ministério da Educação. Programa Mais Educação: Passo a passo. Brasília, 2011. Disponível em:

$<$ http://portal.mec.gov.br/index.php?option=com_docman\&view=download\&alias=8145-epasso-a-passo-mais-educacao-pdf\&Itemid=30192> . Acesso em: 15 jul. 2018.

BRASIL. Ministério da Educação. Secretaria de Educação Básica. Manual operacional de educação integral. Brasília, 2014. Disponível:

$<$ http://portal.mec.gov.br/index.php?option=com_docman\&view=download\&alias=1584 2manual-operacional-de-educacao-integral-2014\&category_slug=junho-

2014pdf\&Itemid=30192>. Acesso em: 22 mar. 2018.

BRASIL. Portaria $\mathrm{n}^{\circ} 1.144$ de 10 de outubro de 2016. Institui o Programa Novo Mais Educação. Diário Oficial da União, Brasília, DF, 11 out. 2016 a.

BRASIL. Ministério da Educação. Programa Novo Mais Educação: Documento orientador - Adesão - Versão 1. Brasília, 2016b. Disponível em:

<http://portal.mec.gov.br/docman/dezembro-2016-pdf/53061-novo-mais-educacaodocumento-orientador-pdf/file>. Acesso em: 15 jul. 2018.

BRASIL. Ministério da Educação. Programa Novo Mais Educação: Caderno de orientações pedagógicas - versão I. Brasília, 2017. Disponível em:

<http://portal.mec.gov.br/index.php?option=com_docman\&view=download\&alias=7083 1pnme-caderno-de-orientacoes-pedagogicas-pdf\&category_slug=agosto-

2017pdf\&Itemid=30192>. Acesso em: 30 abr. 2018. 
BRASIL. Ministério da Educação. Programa Novo Mais Educação: Caderno de orientações pedagógicas - versão II. Brasília, 2018. Disponível em:

$<$ http://portal.mec.gov.br/index.php?option=com_docman\&view=download\&alias=90251caderno-orientador-pnme\&category_slug=junho-2018-pdf\&Itemid=30192>. Acesso em: 02 set. 2018 .

CARDOSO, Heloana. Avaliação de textos produzidos na aula de língua portuguesa: abordagens teóricas, questões didático metodológicas e suas repercussões. 2013. Dissertação (Mestrado em Língua Portuguesa). Universidade do Estado do Rio de Janeiro, Rio de Janeiro, 2013.

CERMINARO, Maria Cecília. Possibilidades do uso de portfólios na aprendizagem da língua materna na escola. 2013. Dissertação (Mestrado em Educação). Universidade Federal de São Carlos, São Carlos, 2013.

CORDEIRO, Gisele Alves da Costa. O olhar de professores sobre o Índice de Desenvolvimento da Educação Básica (Ideb): possibilidades e limitações. 2014. Dissertação (Mestrado em Educação). Pontifícia Universidade Católica de São Paulo, São Paulo, 2014.

CORRÊA, Tânia Regina dos Santos Godoy. Os reflexos do SAEB/ Prova Brasil nas práticas pedagógicas de língua portuguesa nas escolas municipais de Costa Rica/MS. 2012. Dissertação (Mestrado em Educação). Universidade Católica Dom Bosco, Campo Grande, 2012.

COSTA, Ildenice Lima. As concepções e práticas avaliativas em Matemática de um grupo de professores do $5^{\circ}$ ano do ensino fundamental e suas relações com a Prova Brasil. 2015. Dissertação (Mestrado em Educação). Universidade de Brasília, Brasília, 2015.

FAVARÃO, Cláudia Fátima de Melo. Avaliação da aprendizagem: concepções e características. 2012. Dissertação (Mestrado em Educação). Universidade Estadual de Londrina, Londrina, 2012.

GALVÃO, Elaine Cristina. O compromisso formativo na avaliação da aprendizagem em química: das concepções às abordagens do erro. 2013. Dissertação (Mestrado em Educação). Universidade Estadual de Londrina, Londrina, 2013.

GARCIA, Rosineide Pereira Mubarack; TENORIO, Robson Moreira. O uso e as potencialidades do feedback processual na avaliação da aprendizagem. In: TENORIO, Robson Moreira; FERREIRA, Rosilda Arruda; LOPES, Uaçai de Magalhães. Avaliação e Resiliência: diagnosticar, negociar e melhorar. Salvador: EDUFBA, 2012. p. 353-375.

GUIMARÃES, Ana Luiza Bernardo. Avaliação da aprendizagem em arte: desvelando realidades. 2010. Dissertação (Mestrado em Educação). Universidade Estadual De Londrina, Londrina, 2010. 
HOLTAPPELS, Heinz Günther; KAMSKI, Ilse; SCHNETZER, Thomas. Qualitätsrahmen für Ganztagsschulen. [pt. Quadro de referência de qualidade para escolas em tempo integral]. In: KAMSKI, Ilse; HOLTAPPELS, Heinz Günter; SCHNETZER, Thomas. Qualität von Ganztagsschule: Konzepte und Orientierungen für die Praxis. Münster: Waxmann, 2009. p. 61-88.

KREISCH, Cristiane. Avaliação formativa no ensino de arte: estudo sobre as propostas e práticas de professores em escolas públicas de Blumenau. 2011. Dissertação (Mestrado em Educação). Universidade Regional de Blumenau, Blumenau, 2011.

LAZARI, Cleuza Brito da Silva de. Avaliação na educação infantil: concepção de professoras do município de Cáceres expressa nos relatórios descritivos de avaliação. 2013. Dissertação (Mestrado em Educação). Universidade do Estado de Mato Grosso, Cáceres, 2013.

LOPES, Maria Tereza Lyra. Representações sociais de avaliação da aprendizagem por pais e professores de alunos dos anos iniciais do ensino fundamental. 2012. Dissertação (Mestrado em Educação). Universidade Estácio de Sá, Rio de Janeiro, 2012.

MARTINS, Angela Maria. A descentralização como eixo das reformas do ensino: uma discussão da literatura. Educação \& Sociedade, Campinas, v. 22, n. 77, p. 28-48, 2001. Disponível em: <http://www.scielo.br/scielo.php?script=sci_arttext\&pid=S010173302001000400003\&lng=en\&nrm=iso>. Acesso em: 25 nov. 2018.

MARTINS, Cláudia Rodrigues de Camargo. Práticas avaliativas formativas no contexto da periferia: limites e possibilidades. 2012. Dissertação (Mestrado em Educação). Universidade Federal de Uberlândia, Uberlândia, 2012.

MENEGÃO, Rita de Cássia Silva Godoi. Impactos da avaliação externa no currículo escolar: percepções de professores e gestores. 2015. Tese (Doutorado em Educação). Universidade Estadual de Campinas, Campinas, 2015.

MILEO, Cláudia Damiani. O significado do erro na avaliação de aprendizagem: entre o ideal e o real apontado por professoras do ensino fundamental I da zona oeste da cidade de São Paulo. 2011. Dissertação (Mestrado em Educação). Pontifícia Universidade Católica De São Paulo, São Paulo, 2011.

NASCIMENTO, Mari Clair Moro. Avaliação da aprendizagem: repercussões de modelos pedagógicos nas concepções docentes. 2012. Dissertação (Mestrado em Educação).

Universidade Estadual de Londrina. Londrina, 2012.

OLIVEIRA, Sandra Maria Coêlho de. A avaliação formativa como regulação da aprendizagem: desafios para a práxis no ensino médio da rede pública estadual de Fortaleza uma análise fenomenológica. 2015. Tese (Doutorado em Educação). Universidade Federal do Ceará, Fortaleza, 2015. 
PEREZ, Leonardo Anselmo. Um estudo sobre o uso de avaliações apoiadas pelas tecnologias. 2015. Dissertação (Mestrado em Matemática). Universidade de São Paulo, São Carlos, 2015.

RABELO, Kamila Santos de Paula. Ensino de geografia e avaliação formativa da aprendizagem: experiências e princípios na rede pública de Goiânia - GO. 2010. Dissertação (Mestrado em Geografia). Universidade Federal de Goiás, Goiânia, 2010.

RIBEIRO, Débora de Lima. Avaliação da aprendizagem e sequência didática no ensino de produção escrita: aspectos formativos. 2014. Dissertação (Mestrado em Linguística e Ensino). Universidade Federal da Paraíba, João Pessoa, 2014.

SALES, José Antonio Santana de. Rendimento escolar dos alunos no Instituto Federal Minas Gerais - campus Bambuí: pensando a disciplina química. 2012. Dissertação (Mestrado em Ciências). Universidade Federal Rural do Rio de Janeiro, Seropédica, 2012.

SANTOS, Solange Maria dos. Práticas avaliativas desenvolvidas por professores de matemática: novos desafios frente aos resultados da avaliação externa da rede de ensino SESI/SP. 2010. (Mestrado em Educação Matemática). Pontifícia Universidade Católica de São Paulo, São Paulo, 2010.

SANTOS, Valdir Sodré dos. Percepções de docentes de matemática de ensino médio em relação ao processo de avaliação da aprendizagem. 2015. Dissertação (Mestrado em Educação). Universidade de Brasília, Brasília, 2015.

SZATKOSKI, Luciane. A Prova Brasil no cotidiano escolar. 2014. Dissertação (Mestrado em Educação). Pontifícia Universidade Católica de São Paulo, São Paulo, 2014.

SCHMITZ, Heike; SOUZA, Maria Celeste Reis Fernandes de. Reflexões sobre possíveis critérios de qualidade da escola em tempo integral. Estudos em Avaliação Educacional, São Paulo, v. 27, n. 65, p. 552 - 581, 2016. Disponível em:

<http://publicacoes.fcc.org.br/ojs/index.php/eae/article/view/3661/3199>. Acesso em: 27 mai. 2018.

SCHMITZ, Heike; KAMSKI, Ilse. Características da escola em tempo integral na Alemanha: um olhar analítico. Revista Brasileira de Educação. Online, v. 23, e 230066, p. 1-19, out. 2018.

SIBILA, Miriam Cristina Cavenaghi. O erro e a avaliação da aprendizagem: concepções de professores. 2012. Dissertação (Mestrado em Educação). Universidade Estadual de Londrina, Londrina, 2012.

SILVA, Denise Mota Pereira da. Raciocínio geográfico e avaliação formativa: uma análise aplicada ao ensino médio. 2014. Dissertação (Mestrado em Geografia). Universidade de Brasília, Brasília, 2014. 
SOARES, Fernanda Luzia Sousa Santos. Ciclos de aprendizagem em São Luís: implicações nas práticas avaliativas. 2012. Dissertação (Mestrado em Educação). Universidade Federal do Maranhão, São Luís, 2012.

XAVIER, Ilda Aparecida. Uma proposta inovadora de avaliação: desafios, limites e perspectivas em uma escola no DF. 2013. Dissertação (Mestrado em Educação). Universidade Católica de Brasília, Brasília, 2013.

\section{$\underline{\text { SOBRE OS AUTORES }}$}

\section{Heike Schmitz}

Doutora em Educação pela Universidade Federal da Bahia (UFBA). Professora da Universidade Federal de Sergipe no Departamento de Educação e no Núcleo de PósGraduação em Educação. Líder do Grupo de Pesquisa em Avaliação, Política, Gestão e Organização da Educação (APOGEU). E-mail: hs.contato.ufs@ gmail.com

\section{Beatriz Noia Souza}

Graduanda em Pedagogia pela Universidade Federal de Sergipe (UFS). e bolsista de Iniciação Científica COPES/UFS. Integrante do Grupo de Pesquisa em Avaliação, Política, Gestão e Organização da Educação (APOGEU). E-mail: beatriz_noia@outlook.com

\section{José Luis Monteiro da Conceição}

Mestre em Educação pela Universidade Federal de Sergipe (UFS). Integrante do Grupo de Pesquisa em Avaliação, Política, Gestão e Organização da Educação (APOGEU). E-mail: luisuneb1@hotmail.com 